\title{
Interactionism in Personality and Social Psychology: An Integrated Approach to Understanding the Mind and Behaviour
}

\author{
KATHERINE J. REYNOLDS ${ }^{1 *}$, JOHN C. TURNER ${ }^{1}$, NYLA R. BRANSCOMBE ${ }^{2}$, \\ KENNETH I. MAVOR ${ }^{1}$, BORIS BIZUMIC ${ }^{1}$ and EMINA SUBAŠI ${ }^{1}$ \\ ${ }^{1}$ Department of Psychology, The Australian National University, Canberra, ACT, Australia \\ ${ }^{2}$ University of Kansas, Kansas, KS, USA
}

\section{Abstract}

In both personality psychology and social psychology there is a trajectory of theory and research that has its roots in Gestalt psychology and interactionism. This work is outlined in this paper along with an exploration of the hitherto neglected points of connection it offers these two fields. In personality psychology the focus is on dynamic interactionism and in social psychology, mainly through social identity theory and self-categorization theory, it is on the interaction between the individual ('I') and group ('we') and how the environment (that includes the perceiver) is given meaning. What emerges is an understanding of the person and behaviour that is more integrated, dynamic and situated. The aim of the paper is to stimulate new lines of theory and research consistent with this view of the person. Copyright (C) 2010 John Wiley \& Sons, Ltd.

Key words: Interactionism, Social Psychology, Personality, Social Identity, Selfcategorisation, Self-concept, Gestalt, Dynamic interactionism, Holistic interactionism, Life-span Perspective, Social influence

\section{INTRODUCTION AND OVERVIEW}

Personality psychology and social psychology are major fields of enquiry that both seek to understand human behaviour. Given this shared focus there has been much discussion about the connections between these two fields (e.g., Baumeister, 1999; Blass, 1984; Swann \& Seyle, 2005) with many viewing interactionism as the potential bridge. We concur that interactionism offers a fruitful direction for both fields and their intersection, although we believe that it is a dynamic interactionism rather than mechanical interactionism that is the key. Dynamic interactionism argues that behaviour is an outcome of the continuous and reciprocal interaction between the person and the situations they encounter (e.g. Endler \&

*Correspondence to: Katherine J. Reynolds, Department of Psychology, The Australian National University, Canberra, ACT 0200, Australia. E-mail: katherine.reynolds@anu.edu.au 
Parker, 1992). This view of interactionism not only connects with social psychology in important ways, but is also aligned with shifts occurring in other areas of psychology where more dynamic or situated models of the person are being embraced and investigated (e.g., social cognition, neuroscience, (epi-)genetics).

To date most of the commentary on the intersection between the two fields has concerned mechanical interactionism, that is, the interaction between 'person' factors and 'situation' factors in explaining behaviour. The concept 'person' typically refers to the stable characteristics that define the individual - either those linked to fixed genes and temperament or individual difference measures - and 'situation' is a catch all term that often is assumed to mean the environment that exists outside of the person. From this perspective, interactionism is a bridge between personality psychology and social psychology because in personality the emphasis is on 'person' factors (e.g. individual differences, traits, dispositions), while in social psychology the concern is the impact of the situation on behaviour (and in particular the impact of the experimental situation). It is argued that exploring the interaction between these components offers a means of connecting these two fields. Much has already been written about the problems and limitations of this approach (e.g. Endler \& Magnusson, 1976; Hogan, 2009; Journal of Research in Personality, Special Issue, 2009).

Dynamic interactionism, on the other hand, has theoretical roots in Gestalt psychology and represents a body of personality theory and research where the 'situation' is not 'outside' of the person but considers the whole situation including the person. From this perspective, it is not possible to explore person factors independent of situation factors and vice versa. Dynamic interactionism is concerned, in the main, with the psychological situation and the way the perceiver gives the situation meaning. It is this situation-specific meaning that is considered of central importance for understanding behaviour.

There is theory and research in social psychology that also shares historical connection with the Gestalt perspective. In this work there is a focus on the interaction between the individual ('I') and group ('we') and, more recently, in self-categorization theory (Turner, Hogg, Oakes, Reicher \& Wetherell, 1987), how the environment (pattern of stimuli) that includes the perceiver is given meaning. The aim of this paper is to describe the critical insights gained from both dynamic interactionism and this perspective in social psychology, in the interests of building a more plausible and integrated approach to understanding the person and behaviour.

With this aim in mind, the paper is divided into three main sections. The first section provides a brief overview of Gestalt psychology and its links to dynamic interactionism. The work that is highlighted is not exhaustive but captures the core developments in this area. There is clear agreement that 'the psychological meaning of the situation is an important determinant of behaviour' (Endler, 1982, p. 181) and that it is the behavioural or psychological situation that is the core feature of the Gestalt view and Lewin's (e.g., 1952) well-known formula explaining behaviour $(\mathrm{B}=f(\mathrm{PE}))$. This overview of early and more recent theory and research is important because it clearly describes the concept of dynamic interactionism.

The second section provides an outline of interactionism in social psychology. This perspective is most clearly represented in the contemporary literature in both social identity theory (Tajfel \& Turner, 1979) and self-categorization theory (Turner et al., 1987). In understanding individual and group behaviour, a distinction is made between defining oneself as an individual ('I') and as a group member ('we'). There has been a focus on explaining how a situation that includes the person is given 'meaning' such that either one's distinctiveness ('I') or similarities with others ('we') becomes salient or psychologically 
operative. In investigating these dynamic self-categorisations and implications for behaviour, it has been necessary to explain the processes through which stimuli (including the self) are given 'meaning'. It is in understanding the process of 'meaning-making' from the vantage point of the perceiver and explaining how such a vantage point varies in systematic ways that may be of particular interest to the dynamic interactionist tradition in personality psychology.

The third section highlights the main themes that emerge in both fields and examines the fit between these themes and broader movements in psychology. The focus on contextdependent meaning and its impact on the person and behaviour, also aligns with broader movements in social cognition (e.g. situated cognition), neuroscience (e.g. brain plasticity) and genetics (e.g. sociogenomics that considers the impact of the social environment on gene action). This convergence of interest across a number of fields places interactionism at the centre of efforts to explain behaviour.

The message of the paper is that to have viable theories of a range of phenomena of interest in both personality psychology and social psychology (e.g. the self, mind, cognition, information processing, memory, behaviour) it is necessary to incorporate all aspects of a person's psychology (individual, group). Both fields need to take seriously the ideas that the self is variable, can be more or less inclusive of others (' $\mathrm{I}$ ' and 'we'), and as the level of self-categorisation varies (along with the associated content of identity), so to will a whole range of other interdependent factors (e.g. norms, feelings, attention to stimuli, sources of influence, information processing). We argue that it is within this framework of interactionism offered by both personality psychology and social psychology real advance will be possible.

\section{INTERACTIONISM IN PERSONALITY PSYCHOLOGY}

In the personality literature, there are many detailed reviews of interactionism (e.g. Ekehammar, 1974; Endler \& Magnusson, 1976; Endler \& Parker, 1992) that include discussions of the trait, situationalism, psychodynamic and interactional models. The aim in this section is to focus on dynamic interactionism, to describe its historical roots in the field of personality and more recent developments. It is only possible to provide a very brief overview of core ideas.

So what is this view of interactionism? In order to understand interactionism it is necessary to appreciate its Gestalt underpinnings and the way Gestalt ideas are reflected in early and contemporary theory and research in personality psychology. Gestalt theory fundamentally argues that there are 'wholes', and that the nature of 'wholes' is not necessarily determined by the separate elements and the piecewise relations between elements. Many disciplines operate in the opposite way, that is, it is assumed that through isolating and understanding the component elements the whole will become known. Gestalt theory examines the 'whole' because it is more than its elements or parts, and it is the 'whole' that is believed to shape and determine the part-processes not the other way around (e.g. Wertheimer, 1924/1938). One typical example used to explain this position is Wertheimer's views on melody where he states 'what is given me by the melody does not arise. . as a secondary process from the sum of the pieces as such. Instead, what takes place in each single part already depends upon what the whole is' (p. 5).

In relation to dynamic interactionism in personality psychology the 'whole' that affects behaviour is considered to be the situation or environment that is inclusive of the person. 
The person and the situation are an irreducible 'whole' that must be studied as the one continuously interdependent unit. In this view of interactionism there is not a 'person' and a 'situation' there is a situation inclusive of the person and a person whose psychological experience in the situation is the main driver of behaviour. Core themes and developments in both early and more contemporary work on dynamic interactionism are outlined in this section.

\section{Early accounts of dynamic interactionism}

These Gestalt ideas have been applied more directly to understanding human behaviour through the work of Koffka (1935), Murray (1938) and Lewin (1935, 1952) (and others; see Ekehammar, 1974). In this work, a distinction is made between the 'geographical' or objective environment and the 'behavioural' or psychological environment. There is an objective situation (geographical, physical environment), an organism and the behavioural (psychological) environment. For Koffka, the relation between the geographical environment (or the stimulus pattern) and behaviour, involves a relation between (a) the geographical and behavioural environment and (b) the behavioural environment and the behaviour. Also both the geographical and behavioural environments are changed through actual behaviour (Koffka, 1935, p. 34).

Murray (1938) also was focused on the organism-environment interaction and differentiated between the physical and psychological environments using the term 'alpha press' for the physical and 'beta press' for the psychological. He argued that the stimulus situation was the total environment to which the 'creature attends and reacts' (p. 40) and is usually responded to as a patterned meaningful whole. He argued that the stimulus situation could be classified as a Gestalt of stimuli that 'appear in the guise of a threat of harm or promise of benefit' to the organism and that organisms 'naturally "classify" the objects in their world in this way' (p. 41). Murray explored in more detail needs or motives such as ambition and accomplishment, achievement and recognition, and affiliation and affection, and the interaction between needs and press in shaping behaviour.

For Lewin the focus is on the behavioural, psychological environment rather than the physical environment noting that the physical environment can be identical for children and adults but the representation of the situation that is 'real' for the individual is very different (see also Ekehammar, 1974). Lewin (1952) states that 'the effect of a given stimulus depends on the stimulus constellation and upon the state of the particular person at that time' (p. 238). The focus was on the 'life space' of the individual 'which consists of the person and the psychological environment as it exists for him' (p. xi).

This information gives a richer understanding to the famous formulation $\mathrm{B}=f(\mathrm{PE})$. Lewin uses the term ' $\mathrm{B}$ ' for 'behaviour' to describe behaviour or any kind of mental event and he includes 'thinking, wishing, striving, valuing, achieving, etc.' (Lewin, 1952, p. xi). The whole situation or environment including the person is described as '(PE)' and this defines the psychological situation or 'life space' (LSp). In fact Lewin describes this explicitly when he writes $\mathrm{B}=f(\mathrm{PE})=f(\mathrm{LSp})$. The person-situation relationship is mutually dependent with reciprocal interaction and should be considered 'one constellation of interdependent factors' (1952, p. 240).

Initially, experimental work on dynamic interactionism focused on situation reactiontype studies (e.g. Endler \& Hunt, 1969). Diagnosis and description of the individual are argued to be improved by examining his or her responses in various kinds of situations. There was a focus on situations as wholes and on the person's experiences, reactions and 
responses based on being a part of the situation. Participants in this work are verbally presented with a number of different situations (e.g. sitting down to dinner, giving a speech before a large group, failing examinations, receiving a summons from police) and their responses are assessed on a number of items leading to the creation of a person $\times$ response $\times$ situation three-dimensional matrix. In this work, that included a number of constructs such as anxiety, honesty, conformity and stress, the person-situation interactions were found to be more important sources of behaviour than persons and situations per se. Studies also have been conducted that include self-report and observations of overt behaviour (see Endler, 1982, for a review).

\section{Recent applications of dynamic interactionism}

More recent examples of how the principles of dynamic interactionism have been developed and extended can be found in Endler and colleagues' work on anxiety (an aspect of personality) and Mischel's work on cognitive-affective personality system theory. In addition, there is a body of work on the developmental perspective of personality across the life span and the dynamic, continuous and reciprocal interaction between the individual and his/her environment (Endler \& Parker, 1992; Magnusson, 1999; see also Roberts \& Caspi, 2003). Theory and research by Endler and colleagues are viewed as part of the tradition of dynamic interactionism and differentiated from Mischel's work which is often considered more situationalist (perhaps because of its social learning emphasis; e.g. Endler, 1982). Mischel makes it clear early on that the social cognitive approach does not 'construe the individual as an empty organism buffeted entirely by situational forces' emphasising that 'the nature and effect of person variables depend on specific interactions between the individual and the psychological conditions of his life' (Mischel, 1973, p. 278).

Endler and colleagues in their interactional model of anxiety (e.g. Endler, 1982; Endler \& Parker, 1992) argue that across different situations individuals may differ in their likelihood of experiencing anxiety (trait anxiety) and within a particular situation individuals may differ in their likelihood of experiencing anxiety (state anxiety). State anxiety is argued to be experienced as an outcome of a person having a specific dimension of trait anxiety and a corresponding situational threat. So, for example, for a person who reports trait anxiety for social evaluation and perceives a situation to be one that involves social evaluation, state anxiety will be higher for this person than for those who score low on the relevant dimension of trait anxiety. State anxiety is not affected when there is no congruence between the specific trait dimension and the perceived threat of the situation for the perceiver (Endler, 1982). Endler and Parker (1992) argue 'this model questions the usefulness of global assessments of individual differences, and advocates the assessment of personality variables such as anxiety from the perspective of the person-in-context' ( $\mathrm{p}$. 190). There is a large body of work that supports this model offered by Endler and colleagues (e.g. Endler, 1982; for more recent work on automatic evaluations, see Perugini \& Prestwich, 2007).

A major theme in the cognitive-affective personality system model (Mischel, 1973; Mischel \& Shoda, 1995) is the recognition that a person can behave differently across situations and that this intraindividual variability is meaningful in understanding personality and behaviour. The variability across situations is not considered as measurement error or uninformative variance that should be 'averaged' in order to gain a person's true underlying score but is a focus of study. 
The basic idea is that each person has a unique personality system comprised of cognitive-affective units (CAUs - patterns of how an individual reacts to situational features referred to as 'if-then' person-situation relations) that form a network of interconnections that are unique to an individual. Certain CAUs, (and their characteristic relationships) become activated when certain situational features are present impacting on cognition, affect and action. In this way, there can be differences in self-expression across situations without the underlying system itself changing.

In support of this theory, Shoda, Mischel and Wright (1994) measured behaviour (e.g. verbal, physical aggression) in a variety of settings at boys' camp (e.g. woodworking, cabin meetings) and interpersonal interactions (e.g. being teased, being praised by an adult). They found that individual behaviour did vary across situations but that to the extent that situations shared similar features there was increased consistency in individual behaviour across them. Mischel and Shoda (1995) draw parallels between their own findings and the situation reaction-type studies described above (e.g. Endler \& Hunt, 1969; Endler \& Magnusson, 1976). As a person experiences situations that contain different psychological features (e.g. interacting with your mother on a family holiday or in the car driving home with your partner) different CAUs and their interrelationships with other units become activated in relation to those features (Mischel, 2004). People can exhibit variability in behaviour across situations but if the psychological features of the situation are similar then more consistency across situations is evident. The fundamental interest of the model is the 'psychological features of the social world and the individual's distinctive patterns of cognition, affect and behaviour' (Mischel \& Shoda, 1995; p. 263).

When considering these two well known and high profile examples of the way dynamic interactionism has been investigated a number of observations can be made. The first is that there is recognition that the person has a system of some form of continuity (e.g. trait anxiety, patterns of how a person reacts in particular situations). The second is that the specific features of the situation as perceived by the 'person-in-context' (which is shaped by this 'continuity') will determine their behaviour in that situation (e.g. state anxiety, stress, aggression). The third observation is that it is not clear how this work is 'dynamic' in the sense that current experiences come to affect one's 'system of continuity' in ways that shape responses to a future encounter. It is not clear how overcoming state anxiety (through perhaps greater exposure to certain events, the use of relaxation techniques, cognitive framing) or having an experience that activates a particular 'if-then' signature, comes to affect a person's resources that they bring to the next situation (e.g. trait anxiety, activation of the same or different CAUs). The reciprocal and dynamic interaction of the person, situation and behaviour is under-conceptualised. Put another way, how within dynamic interactionism is it possible to account for underlying trait change or CAU change? This work seems to focus on variation from situation to situation and how this might occur but focuses less on how the system of personality itself may be affected by processes of dynamic interactionism. The possibility for fundamental person continuity and change is recognised more explicitly in the developmental or life span perspective.

\section{Dynamic interactionism and the life span perspective}

This perspective not only focuses on the person as a whole including biological, psychological and social-contextual processes but also assesses the person across time to better understand personality continuity and change. Magnusson and colleagues use the term holistic interactionism to describe their focus on personality development. In this 
work there is an emphasis on how the person develops as an integrated whole across the life course and the person is understood as an active, intentional part of a complex and dynamic person-environment system. All aspects of individual functioning (perceptions, cognitions, values, biological factors, conduct) are viewed as part of a self-organising system within which any element has to be understood within the total functioning of the individual. The way an environment is perceived and interpreted plays an important role in psychological and biological functioning and such functioning is viewed as being extremely sensitive to environmental settings. The "character of the environment, particularly the environment as it is perceived and interpreted by the individual' is argued to be of central importance (Magnusson \& Törestad, 1993, p. 437).

Magnusson and Törestad (1993) outline an example where a situation is interpreted by a person as being threatening or demanding such as sitting for an exam. The act of interpreting a situation as a 'threat' will lead to the excretion of adrenaline (via the adrenal glands) which triggers other physiological responses. The interplay between cognition and physiology will lead to an emotional response such as fear and arousal. These cognitivephysiological-emotional reactions will affect his or her ongoing interpretation of the situation in a 'continuous loop of reciprocal interaction' (p. 437) affecting goals, motivations and behaviour (e.g. a desire to study, concentration). It is argued that across time, the interplay between these systems can contribute to changes in a particular system or related systems (e.g. immune system).

Roberts and Caspi (2003) also present a life-span perspective. The focus of these researchers has been on the issue of trait continuity and change, and understanding personality across the life course. In this work, Roberts and Caspi acknowledge the possible impact of new experiences, social roles and identity development. People are viewed as open systems that exhibit both continuity and change as a function of their life experiences and the development of social roles and identity structures. In describing identity, Roberts and Caspi (2003) refer to Marcia (1980) where identity is viewed as a 'self-structure - an internal, self-constructed, dynamic organisation of drives, abilities, beliefs and individual history' (p. 159) and Burke (1991) who defined identity 'as a set of meanings applied to the self in a social role or situation defining what it means to be who one is' (p. 837). In this work identity is synonymous with one's self-view or selfdefinition and for Burke (1991) this 'set of meanings' may change with social roles and situations.

A strong sense of identity (belief, conviction, purpose) in one's life, for example, can provide an anchor point for life decisions that structure experiences in particular ways serving to maintain continuity. McAdams (1996) argues that modern society demands a 'telling of the self' where there is overall unity and purpose between the past, present and future self. These narratives or stories integrate the self into society and provide a sense of self-stability. Furthermore, as active agents in the social world, perceivers are argued to seek out and maintain environments that 'fit' their stories, tendencies and dispositions promoting behavioural consistency and limiting opportunities for change. This continuity is achieved through the way situations are selected and interpreted. It is recognised through the 'corresponsive principal' that the impact of life experiences on the person typically is 'to deepen the characteristics that lead a person to those experiences in the first place' (Roberts \& Caspi, 2003, p, 470).

It is also acknowledged, however, that across the life cycle often there are new agerelated experiences, roles and opportunities that arise and/or are chosen such as career, promotion, parenthood, change in partner status, retirement, and ageing. Situations can 
change in ways that impact on the person. New roles, for example, can be internalised affecting one's sense of self and can account for evidence of both continuity and change in the person across time and situations. In this work there is a deeper consideration of the way person-environment continuities actually may account for personality continuities (Roberts and Caspi, 2003). Furthermore, there is a recognition that, under certain conditions, people can internalise different ways of being as a function of role and other changes.

\section{Summary: Interactionism in personality psychology}

There is a significant body of work that is concerned with dynamic interactionism in personality psychology. A person's subjective conception of the situation (of which he/she is part) emerges as a central force in explaining behaviour. It is recognised that a person has specific expectancies and hypotheses about the situation and behavioural possibilities in the situation (Mischel, 1973). Such expectancies (along with other factors) motivate certain features of the stimulus pattern to be attended to and activate particular 'states' or 'if-then signatures' or 'interpretations' that are paramount in explaining behaviour. There is also a recognition that as one's identity changes as a function of social roles and identity development, so too can aspects of personality (e.g. traits, sense of self). These processes are believed to help explain continuity and change in the person.

As is discussed in more detail in the next section, in social psychology there is also an emphasis on identity. The way identity is understood in this work is not necessarily tied to social roles. Social roles are viewed as a group membership that can become psychologically significant to a person (e.g. mother, worker, academic) shaping action in line with the expectations and norms associated with that role. This social psychological perspective offers a different view of the person because it is recognised that a person is both an individual ('I' and 'me') and group member ('we' and 'us').

Descriptions by Koffka (1935) and Angyal (1951) are informative in understanding this notion of the group ('we'). Koffka (1935) gives an example of the psychological group when he argues that a person can enter a room and see people in the room as a group, separate from all other objects. At first on entering the room the person does not belong to the group, however, at a later point in time he or she may. This new group that now contains these other people and the person is explained in terms of perceived similarity with them. Koffka (1935) argues that "we see through vision and audition, persons, that is objects endowed with the same kind of spontaneity as we possess, with purpose and hesitation... we experience ourselves also as persons' (p. 655). This similarity or equality is argued to be the basis for psychological 'group-we' formation (p. 651). Furthermore, there is a recognition that the characteristics of the person can make this process easier or harder with a view that 'a sophisticated person will fall in easily with other sophisticated or even blasé ones, and will readily develop in his field a psychological group to which they and he will belong, a direct and simple person will not easily find himself as part of 'we' if he is thrown in with a number of sophisticated people. Similarly to be sad tends to exclude one from a gay group' (p. 655).

Also, Angyal (1951) uses language that may resonate more with a personality audience to describe this other level of self-experience. He argues that the person is both an organiser of his or her own personal world but is also a participant with others in a superordinate whole to which he or she belongs. Experiencing others as members of a larger whole with a sense of belongingness and sameness brings another facet of his or her nature into 
manifestation. Through work on interactionism in social psychology, what has emerged is a more detailed understanding of 'group-we' and the 'superordinate whole' and implications for understanding the person. This analysis perhaps offers personality psychology a way to approach group as well as individual behaviour and in the process offers a more integrated view of the person.

\section{INTERACTIONISM IN SOCIAL PSYCHOLOGY}

There is a Gestalt tradition in social psychology that is most clearly developed through the work of Asch, Sherif, Lewin, Bruner, Tajfel and Turner. In this work, it is recognised that human systems are comprised of both individuals and groups and therefore, the person is both an individual and group member. There are emergent psychological processes, 'wholes', related to group life that are overlooked or misattributed if one focuses on the individual as an isolated 'part'. Social norms, shared values, influence and persuasion, shared emotions and shared goals, all are collective products. They arise through coordinated activity that shape the social system (e.g. power structures, laws, policies, conventions, culture) and, in turn, structure the groups and individuals of which the system is comprised (what is valued or not, considered appropriate or inappropriate, right or wrong). Through social interaction and shared activities, then, the mind (e.g. thoughts, emotions, memory, perception, imagination) and mental functioning are qualitatively transformed - the so-called mind-society interaction or interactionism. In social psychology, interactionism is contrasted with reductionism or individualism where explanations of such collective phenomena are reduced to asocial, non-contextualised, abstract causes (e.g. temperament, mood, biology, individual differences, limitations and biases of cognition; see Turner \& Oakes, 1997 for a more detailed discussion).

This view of interactionism offered by social psychology and, in particular, social identity (Tajfel \& Turner, 1979) and self-categorization (Turner et al., 1987; Turner, Oakes, Haslam \& McGarty, 1994) theories, has a number of implications for personality psychology. First, there is a view that the person is both as an individual and group member and that one's self-definition can vary from one level to the other (i.e. variable self-definition or self-categorisations). Second, there is a recognition that knowledge, expectations and observations about how similar others behave can have a direct impact on explaining a person's own behaviour in a given situation (i.e. social influence and social behaviour). Third, it identifies that in understanding the person it is necessary to explain the potential interplay between these two levels of self-experience (i.e. interdependence between group and personality processes). Each of these areas will be addressed in turn.

\section{Variable nature of the self-categorization process}

The concept of personal identity or the personal self ('I') is used to describe situations where individuals perceive themselves to be distinct and different from others (available for comparison). The concept of social identity or the social self ('we') refers to an individual's 'knowledge that he [or she] belongs to certain groups together with some emotional and value significance to him [or her] of the group membership' (Tajfel, 1972, p. 31). Importantly, the term social identity does not necessarily refer to demographic, sociological or role groups (e.g. women, those with low socio-economic status, or academics). The term 
refers to psychological groups where an individual perceives him-or herself as being a member because the group is self-relevant and self-defining (Turner, 1982, 1985).

More specifically, in self-categorization theory, it is argued that people can define or categorise themselves at different levels of abstraction, for example, at the interpersonal level (where self is defined as a unique individual relative to others available for comparison), at the intergroup level (where self is defined as being a group member in contrast to a relevant outgroup) and at the superordinate level (where self is defined as a human being in contrast to other life-forms). Self-categorisations at levels less inclusive than the individual person are also possible. Intrapersonal identities (e.g. the public and private me, the 'me' as defined before and after therapy, Higgins, 1989) reflect comparisons within the personal self.

In this exploration of levels of self-categorisation, all the different aspects of human experience (as an individual 'I' and group member 'we') are addressed providing a more integrated view of the whole person. Using the same terminology as Kluckhohn and Murray (1953), it is possible to explain how the individual person is like no other person, how the individual person is like some other persons, and how the individual person is like all other persons. Given this normal variation in the self-process from personal to collective, the same person may express different views depending on the salient context. It is difficult to reconcile these levels of self-categorisation and the concept of personality defined as the stable characteristics of the (individual) person. Most obviously, personality or individuality could be defined as one's sense of self as an individual who is different and unique from others in the context of interest.

In self-categorization theory a focus has been on explaining the shift between 'I' and 'we' and what determines which identity (and its associated content) will become relevant and meaningful in a particular situation. The categorisation process is the mechanism that provides stimuli (including the self) with meaning. It is this meaning-making process that is most relevant to dynamic interactionism and the associated emphasis on the psychological situation. It is argued that a particular self-categorisation and associated attitudes and behaviours are an outcome of the dynamic interaction between perceiver readiness factors and comparative and normative fit factors. It is the resulting salient selfcategorisation that may be as an individual or group member, that is informative in understanding and explaining one's affect, attitudes and behaviour in a given situation.

Perceiver readiness builds on Bruner's (1957) notion of accessibility and relates to 'the tendency for certain ways of categorising to be more accessible as a function of perceivers' expectations, motives, values and goals' (Oakes, Haslam \& Turner, 1994, p. 199). Importantly, the concept of perceiver readiness highlights the point that perception is relative to the perceiver; 'that we see the world veridically but in a way that is useful and relevant to our goals and needs and stamped by our values and theories' (Oakes et al., 1994, p. 201; Turner et al., 1994; Turner \& Oakes, 1997). In this way, one's experiences, knowledge and theories constrain the perceiver's 'readiness' to construct particular categories. There are links here also to work by Rosch, Medin, and Barsalou and colleagues which are described in more detail in Oakes et al. (1994).

Experiences as a group member (and not just as an individual) shape the resources a perceiver brings to a situation and their readiness to categorise a situation in particular ways. Turner (1987) argues that the 'the centrality and evaluative importance of a group membership in self-definition, is a major determinant of accessibility’ (p. 55). He goes on to discuss research that suggests that highly prejudiced people, for whom being 'white' could be a very important aspect of their self-definition, may be more perceptually ready to 
categorise stimuli (e.g. a meeting where Anglo-Australians and Indigenous Australians are present) in racial terms. Likewise, for those whose political affiliation or gender is very important may be 'readier' to try and categorise stimulus information along these dimensions. Drawing on Koffka (1935) an expectation that one is more 'unsophisticated' compared to others or 'sad', can affect one's readiness to perceive certain similarities and differences. Using different terminology perceiver readiness could be understood as 'tuning' the perceiver to particular stimulus features in a given social context (Swann \& Seyle, 2005).

Regardless of how 'ready' a perceiver is to judge a situation in a particular way, however, there must be evidence in the situation that sustains such a categorisation. Perceiver readiness and the perceived features of the stimulus environment interact to produce context-specific categorisation. The meta-contrast principle is the basis of comparative fit (Turner, 1985). This principle states that in a given situation, stimuli will be categorised as the same when the average differences perceived between them (intraclass differences) are less than the differences between them and other stimuli (interclass differences) within the comparative context.

Categories are formed through a context specific assessment of similarity and difference. For example, an individual would self-categorise more as a social psychologist ('us') rather than individual academic ('I') at a Departmental staff meeting, to the extent that during discussion, the differences between the person and other social psychologists were perceived to be less than the differences between social psychologists and personality psychologists in that particular social context (e.g. discussions on a new appointment in the Department). Based on the principles of comparative fit, in another situation when clinical psychologists were included in the frame of reference because they started to make a pitch for a clinician to fill the new position, social and personality psychologists could be seen as more similar ('us') and unified in comparison to the clinical group ('them'; see Haslam \& Turner, 1992; Haslam, Turner, Oakes, McGarty \& Hayes, 1992).

Also impressions of one's own sense of self as a unique and distinct individual ('who am I') are viewed as an act of categorisation. An individual may be perceived as sophisticated or sad to the extent that the behavioural variability displayed by the person in relation to this characteristic across time and occasions, was less than the variability on this dimension between the individual and other individuals available for comparison (also see Plaks, Shafer \& Shoda, 2003). As is discussed in more detail below, the formation of a person category follows the same process as the formation of a social category (Mavor, 2004, Oakes, 1987; Oakes et al., 1994; Reynolds \& Oakes, 2000).

However, to categorise oneself and others as social and personality psychologists or as sophisticated or sad, there must not only be similarities within and differences between the stimuli, but these must be in the direction that makes sense for the perceiver on the relevant dimensions of comparison. So there is a content as well as a structural dimension to categorisation. The similarities amongst social psychologists (and difference from personality psychologists) must make sense based one people's normative expectations about these groups. Normative fit relates to the content dimension, the direction or meaning of the categorisation in a particular social environment (see Oakes, 1987).

Adopting terminology more typically encountered in personality psychology, the readiness $\times$ fit categorisation process explains in detail the relationship between the pattern of stimuli encountered by the perceiver in a given situation and the psychological environment that emerges for the perceiver to make sense of this stimuli (which is informed by broader values, theories and knowledge). An important point of distinction, however, is 
that the way 'meaning' is established also includes the self and can lead to one's own sense of self or self-categorisation varying (e.g. 'I' or 'we').

Many studies have demonstrated qualitative shifts in the psychology of the person depending on the comparative context and associated salience of either one's personal identity ('I') or social identity ('we'; see Onorato \& Turner, 2002 for a review). Onorato and Turner (2004), for example, explored self-ratings in two different comparative contexts: as individuals, and as women compared to men in an intergroup context. Using the same procedures as Markus (1977), initially participants were classified as independent schematics (i.e. they possessed core self-schema for independence), dependent schematics (i.e. they possessed core self-schema for dependence), aschematics (i.e. neutral with respect to (in)dependence) and unclassifiable (unclassified participants). These classifications are considered to be 'relatively unresponsive to changes in one's social circumstances' (Markus \& Wurf, 1987, p. 306) and in this way share many of the same assumptions as those that underpin personality traits.

As part of a supposedly unrelated study, participants, then, were placed in an intergroup context in which in same-sex discussion groups they discussed the degree to which stereotypical traits were more typical of one sex compared to the other. So, women had to discuss the degree to which women were more tactful, cautious and dependent than men while men had to discuss the degree to which the traits dominant, aggressive and independent were more typical of men than women. They then completed a computer task where they had to think of themselves in terms of their own sex compared to the other (e.g. men compared to women) and indicate the degree to which they thought they or the relevant contrasting group (men or women) had the characteristic of interest. It was found that in the intergroup context, irrespective of their person self-schemata, both males and females tended to rate themselves in terms of their own gender stereotypes. Dependent and unclassified males behaved as independent schematics, and independent and unclassified females behaved as dependent schematics.

In a second study, high or low independent schematics were identified in the sample and made self-ratings under conditions of salient personal or social identity. Again, individual differences in self-reported independence tended to be eliminated under conditions of salient social identity, where people self-stereotyped in terms of the shared ingroup identity, but reappeared in line with self-schemata where personal identity was salient. Thus a woman who defined herself as consistently and strongly independent would rate herself in this way and different from 'dependents' under personal identity conditions, but rate herself as dependent like other women when social identity was to the fore. Guimond, Chatard, Martinot, Crisp and Redersdorff (2006) have replicated these findings with respect to defining the self in line with gender stereotypes (also see Guimond et al., 2007).

A core idea of this approach is that one's self-categorisation is variable and contextdependent being shaped and constrained by the resources a perceiver brings to the situation (perceiver readiness) and the way stimuli in the situation (that includes the self) are given meaning (fit). The self-concept or cognitive representation of the self in this view is not equated with the personal self but it is recognised that more inclusive levels of self ('we') are possible and just as valid and under some conditions more important (Turner \& Onorato, 1999). Turner (2006) makes this point clearly when he argues that a whole range of behaviours highly studied in psychology (e.g. When do we co-operate rather than compete? When are we open to others' ideas rather than rejecting them? When do we feel respect rather than disrespect? When do we act in united ways? When do we feel empathy rather than indifference?) depend at some level, on a shift from a person defining him or herself as an 'I', 
as an individual person who is different from other individual persons, to a 'we' which is inclusive of others who are distinct from 'them'.

\section{Social influence and social behaviour}

When people self-categorise or identify with a particular ingroup, the norms, values and beliefs that define the group are internalised and influence the attitudes and behaviour of group members. The stronger one's identification with a particular group the more likely it is that he/she will behave intrinsically in line with the aspects that define the group. Under these conditions, other group members can come to have an impact on one's own thoughts, attitudes and behaviours. It is this process of social influence that is important in explaining how being a group member can come to affect significantly those acting in terms of those groups.

Work by Sherif and Asch, for example, has demonstrated that others' who are perceived to be like oneself can influence one's own behaviour (e.g. judgment of lines, movement of light). In the Asch paradigm (Asch, 1955), for example, there was evidence that when people judged to be similar to oneself made different judgments from one's own (e.g. they made incorrect judgments about the length of lines), this eroded confidence and affected the individual's own responses. Building on these and related findings, it is argued in selfcategorization theory that others 'like us' play an important role in shaping the psychology of the person.

When people are considered to be in the same class of stimuli ('us' rather than 'them') they are cognitively grouped as similar perceivers confronting the same stimulus situation. This similarity leads people to tend to agree, it also creates an expectation that they ought to agree and respond in the same way (in reactions, judgment, attitudes, behaviour) and motivates people to bring such agreement about. In terms of explaining more specifically how 'others' come to affect one's own attitudes and behaviour, the stages can be summarised as follows: (1) individuals define themselves as members of a distinct social category, (2) they learn or develop the appropriate, expected, desirable behaviours that are correlated with category membership, and differentiate it from other categories (e.g. the stereotypical norm), (3) they assign the norms and attributes of the category to themselves (internalisation) and (4) thus their behaviour becomes normative as their category membership becomes more salient (Turner, 1982; Turner, 1987). Internalisation is critical to the emergent social norms having an impact on one's attitudes and behaviour (see also Kelman, 1958, 2006) and is affected by the degree to which individuals consider themselves psychologically to be members of the particular group. Furthermore, because other ingroup members are viewed as similar to oneself, they become a valid source of information and a testing ground for one's own views on relevant dimensions. Through these processes ingroup members can shape each others' norms, values and beliefs in significant ways (re)defining 'who we are' and 'what we do'.

The basic point is that as different people come to be defined as similar to oneself (e.g. in a new work place) there are new opportunities for social influence which can affirm current practices or fuel change. This analysis of psychological similarity with others and associated social influence provides a mechanism for explaining how 'who we are' can shape 'who I am' (and vice versa). Put in more Lewinian-type terminology in understanding $\mathrm{B}=f(\mathrm{PE})$ it is necessary to recognise that $(\mathrm{PE})$ - the psychological environment - is affected by our common social location with others and the knowledge, 
norms and expectations that flow from this common location. It is the emergence of this sense of similarity to others and associated processes of social influence that helps explain how personal change becomes possible. This analysis may be useful in understanding the mechanisms that underpin personality continuity and change.

\section{Group and personality processes}

There is broad acceptance of the idea that a person can belong to many different groups and that when a particular group becomes psychologically salient the social norms related to that identity will come to shape behaviour in significant ways. One's group-based identities are recognised as being variable and context-dependent. Often, though, this variability at the group-level is contrasted with the relatively stable and enduring features of personal identity or the personal self. A key contribution self-categorization theory is that the social comparative features that define one's social identity in a given context, also can be applied to understand one's self-definition as an individual (Oakes et al., 1994; Reynolds \& Oakes, 2000; Reynolds \& Turner, 2006; Turner, Reynolds, Haslam \& Veenstra, 2006; Haslam, Ellemers, Reicher, Reynolds \& Schmitt, 2010). This argument means that one's sense of self as an individual ('who I am') is forged through social comparison and can vary depending on the social comparative context.

The impact of social comparison on the cognitive representation of the self is relevant to personality psychology. Many personality measures include an instruction such as 'think of yourself across situations and time' or 'think of yourself compared to others the same age and sex as you' (a comparison that stays constant for the person across the life course). These instructions define a particular comparative context that affects one's salient selfviews. Thus variations in the nature of the comparative context itself could produce changes in one's self-ratings. For example, if you were asked to describe how you are different from other Australians, you might characterise yourself as particularly 'down-toearth', but if you were indicating how you are different from other university students you might say that you are rather 'uptight'. If your group of friends was considered when describing yourself, you might say you are an 'anxious person', even though you would not describe yourself in this way if you were thinking of women, or scientists, or some other group that you belong to as the comparison. The point is that the content that is generated to describe personal identity depends on some comparative reference and this can result in different (or the same) self-descriptors being generated depending on the context (also see Andersen \& Chen, 2002; Dweck, 1996). In a sense individual differences can be thought about in this framework as relative individual differences because categorisation and 'meaning' involves comparison and contrast (Onorato \& Turner, 2004).

One of the challenges is to show that the same categorisation processes that are associated with group-level phenomena also are relevant to individual-level phenomena (e.g. Mavor, Reynolds \& Skorich, 2010; Reynolds \& Oakes, 2000; Stapel \& Koomen, 2001; Stapel \& Van der Zee, 2006). Along these lines, Mavor et al. (2010) have investigated the impact of having people complete self-ratings in contexts where self and others are evaluated alone (intrapersonal context) or in comparison to each other (interpersonal context). Just as one's own group is viewed as being more variable and heterogenous when the group is judged alone (an intragroup context) rather than in comparison to a relevant outgroup (an intergroup context; e.g. Haslam, Turner, McGarty \& Oakes, 1995), so too personal self-judgments can vary depending on whether the comparative context is intrapersonal (where the self alone is judged) or interpersonal 
(where the self is compared to friends, say). It is also the case that depending on features of the comparative context self-judgments can be more or less dispositional (versus situational). Thus if individuals compare themselves to others (interpersonal) rather than making assessments in isolation (intrapersonal), they are more likely to characterise themselves in a dispositional way. The interpersonal context accentuates the similarities and differences between the person and comparison other, leading to a strong sense of one's self-defining features. In this way, the comparative context has an impact on personal self-categorisations and such categorisations also can be variable depending on the comparison frame of reference.

In addition, there is evidence of the impact social identity processes can have on a range of individual-level characteristics and abilities (cognitive performance, well-being, Big 5 personality; Reynolds, Turner, Branscombe \& Mavor, 2005). Work on stereotype or social identity threat clearly demonstrates that when people define themselves in relation to certain group memberships that have negative meaning this can have an impact on cognitive ability (e.g. intelligence) and performance on those dimensions that define the stereotype of the group (Steele \& Aronson, 1995; Steele, Spencer \& Aronson, 2002). In the BBC Experiment, Reicher and Haslam (2006) examined the impact of social structural factors and group processes on a range of more clinical outcomes (e.g. depression, anxiety, paranoia). Also, Williams, Turkheimer, Magee \& Guterbock (2008) report findings showing that contamination anxiety (an aspect of obsessive-compulsive disorder) is not only affected by ethnic category membership (e.g. African American or European American), but also by whether the ethnic identity is salient when completing relevant measures. In a large scale study of staff and students in high schools (years 7-10), Bizumic, Reynolds, Turner, Bromhead \& Subašić (2009) show that social identity is significantly related to, and mediates the relationship between, organisational factors and individual psychological well-being (e.g. self-esteem, positive affect and job involvement, but also negative aspects, such as depression, anxiety, loss of emotional control and aggressive and disruptive behaviour).

In one series of preliminary studies related to personality specifically, participants complete standard personality measures under conditions where certain ingroup-outgroup comparisons were made salient affecting participants social identity as an Australian (versus American), student (of University $X$ versus $Y$ ) or Non-Aboriginal (versus Aboriginal) Australian. Findings suggested that Neuroticism scores increased in the NonAboriginal identity condition compared to the other two conditions. In a follow-up study, participants completed all six sub-scales of Neuroticism (anger, anxiety, depression, immoderation, self-consciousness and vulnerability; Goldberg, 1999, IPIP-NEO) at one point in time (phase 1) and also again under conditions where their Non-Aboriginal Australian versus Aboriginal Australian social identity was made salient (phase 2). Results indicated that across time (approx. 8 weeks) there was a high level of consistency in participants reported Neuroticism. There also was evidence of a significant impact of the social identity manipulation and one's identification as a Non-Aboriginal Australian in explaining personality assessed at phase 2 . Findings suggested that it was the depression sub-scale of the Neuroticism measure that was impacted most strongly as a result of NonAboriginal identity (Reynolds, Turner, Branscombe, Mavor, Subašić \& Bizumic, 2009). It was explained that in this condition, comparisons between Non-Aboriginal and Aboriginal Australians may have oriented participants towards collective emotions and stereotypes that are related to what has been a negative intergroup comparison in Australia's history (see Branscombe \& Doojse, 2004). 
This work is in the early stages but shows that self-reported personality may be malleable as a function of a person's salient social identity (and its associated meaning) pointing to the role social identity may play in personality processes. A chronically salient social identity may come (depending on its content or meaning) to have significant impact on the person in the way self-categorization theory describes. Currently, research is being conducted to investigate using more naturalistic longitudinal designs the interplay between social identity processes and personality outcomes in a more reciprocal dynamic way. An initial focus is on how personality is affected by (a) changes in the meaning of a particular group membership and its psychological significance to members (e.g. as a function of organisational change) and (b) one's experiences as a group member and processes of social influence across time.

If it is the case that personality is affected by contemporary social identity processes then one could expect that along with changes to the nature of social identity as a result of broader social and political processes or because of incremental personal change (e.g. attending university later in life, change social roles, living in a different country, changing careers, finding religion), there could be a deep impact on the person. As different people come to be defined as similar to oneself, there are new opportunities for social influence, the emergence of different background knowledge and the formation of different selfviews. One's theories, expectations and beliefs about oneself and the world can change. The general point is that contemporary events - and the identities and social influence they engender - can impact on personhood in significant ways (Reicher \& Haslam, 2006; Reynolds, Turner, Branscombe \& Mavor, 2005; Reynolds \& Turner, 2006; Turner et al., 2006).

\section{Summary: Interactionism in social psychology}

Categorisation is the process through which stimuli including the self are given meaning. Attitudes, feelings and actions flow from this self-categorisation process. In order to explain behaviour-in-context it is necessary to explain self-categorisation-in-context. Furthermore, the social psychological analysis of categorisation is relevant to personality psychology and dynamic interactionism, because it outlines a process through which (a) the psychological behavioural environment - the psychological meaning of a situation (including in relation to the self) - emerges for the perceiver and (b) social identity, group norms and social influence can come to affect continuity and change in the person.

\section{COMMON AND DIVERGENT THEMES ON INTERACTIONISM AND CONSEQUENCES FOR FUTURE THEORY AND RESEARCH}

Drawing on these brief overviews of theory and research on interactionism in personality psychology and social psychology it is possible to identify a number of themes including the following:

(1) Interactionism in personality and social psychology both place the total environment including its psychological meaning as central in explaining behaviour.

(2) There is the possibility for both continuity and change in the person across contexts depending on changes in one's circumstances and how these are interpreted and given meaning by the perceiver. 
(3) For social psychology, in particular, in explaining behaviour it is necessary to recognise the ongoing impact of psychological group memberships and associated processes of social influence.

The implications of each of these themes for the field, obstacles to the acceptance of these arguments and possible future directions for theory and research are described in more detail in this section.

\section{A focus on the psychological environment and 'meaning'}

There has been much discussion in social psychology and personality psychology about the psychological behavioural environment and the meaning of the situation for the perceiver. It also has been argued that one's self-definition or self-categorisation varies based on these same processes. Two main descriptions of the way meaning emerges for perceivers are found in cognitive-affective personality system theory and self-categorization theory. Mischel and colleagues have focused on explaining how particular information becomes activated for the perceiver as a function of the match between situational features and the cognitive affective interrelationships in memory. In self-categorization theory, the categorisation process is a meaning making process. It explains the way perceivers define (characterise, perceive, judge) themselves and others in a given context. From a selfcategorization theory perspective 'meaning depends on context, and categorisation is able to fulfil its meaning-giving function in perception by representing stimuli-in-context' (Oakes et al., 1994, p. 124).

One of the main obstacles or blockages to these ideas is referred to as the 'boxology' model of encoding, memory and retrieval (Smith \& Conrey, 2007; Smith \& Semin, 2004). Recognition that one's judgment, perception or categorisation of the situation (including the self) is more dynamic and situation-dependent requires a rejection of the idea that information in memory is first stored and then retrieved and that concepts are 'stored as discrete units' (Mischel, 2004, p. 10). There needs to be a movement away from the view that there are 'pre-formed, already stored self-concepts (whose meaning is defined prior to their activation)' towards an acceptance that the self is a 'flexible, constructive process of judgment and meaningful inference in which varying self-categories are created to fit the perceiver's relationship to social reality' (Turner et al. 1994, p. 458). It is also necessary to resolve how there can be a continuity of self-knowledge that can come to the fore in a particular context without this knowledge being stored in set category-attribute configurations.

This zeitgeist, though, may be changing, creating an environment more aligned with the contextualised view. Increasingly, in social cognition there is recognition that "cognition is situated - not isolated in inner representations and processes but causally interdependent with the current physical and social environment' (Smith \& Semin, 2007, p. 134). The adaptive features of cognition and its context specificity are recognised as well as the importance of the perceivers' current social motives and goals and relationship with others (Smith \& Semin, 2007). This emerging convergence in personality, social and cognitive psychology on context-dependent processes offers some possibility that future theory and research will be able to make further advance in the area of construction of meaning.

\section{Embracing the idea of (possible) person variability}

In both dynamic interactionism and self-categorization theory there is recognition that causes for continuity and change in the person are located in the dynamic interaction 
between persons and situations. For Mischel, if-then signatures enable the same or different self-expression across situations but without the underlying personality system itself changing. Within self-categorization theory, it is argued that if stable social and psychological conditions prevail self-categorisations will be formed in similar ways in similar situations, but as conditions change different personal or social self-categorisations can emerge. It also needs to be emphasised that there is not a denial of stability in either perspective. Turner et al. (2006, p. 256) argue that self-categorisation 'is not free to vary in any which way, but is always constrained by the motives, goals, values, experience, theories and knowledge the perceiver brings to the situation'. For Mischel and Shoda (1995) there is an organisation of CAUs that is stable and distinctive for each individual. We concur that there can be broad stable consistencies in the person and behaviour, but these 'should not be reified into fixed personality structures' (Turner et al., 2006, p. 25; Magnusson \& Törestad, 1993).

A point of distinction with self-categorization theory, is that it is argued that one's background knowledge (perceiver readiness) can be transformed, updated and reinterpreted in light of the current circumstances. It is argued that different interpretations of knowledge and new knowledge can be gained which can have a fundamental impact on the psychology of the person (and their self-views, narratives, values, beliefs, goals, ideologies). Using language more consistent with the cognitive-affective personality system, this point concerns the actual formation and updating of the CAUs themselves and the relations between units that are likely to become activated given experiences in a given situation. In this sense the self-categorization theory analysis is truly dynamic with arguments that under certain conditions the 'self-system' can be updated and changed.

Based on self-categorization theory it is possible to outline a number of paths through which continuity and change to the resources a person brings to a situation can occur (also see next section for more detail). Along with other factors, the centrality and importance of a particular self-definition to an individual is likely to increase as a function of the number of social situations where the individual acts in terms of that self-definition (McGarty, 1999; Spears, Jetten \& Doosje, 2001; Tajfel, 1978; Turner et al., 1987). The influence of others related to a particular self-definition (e.g. leaders, authorities) also will play an important role in shaping the significance of a particular identity and knowledge associated with it. One's beliefs, theories and knowledge about the world and oneself are developed and validated or changed through interactions with those that are categorised as being similar to oneself (e.g. Turner, 1991).

There is more work to be done, in investigating the specific processes at work in explaining how stable knowledge and stable situational elements privilege particular selfcategorisations. In addition, through research on perceiver readiness specifically, it is necessary to better understand how knowledge patterns change for the perceiver therefore framing the readiness to categorise a situation (and the self) in a particular way. Techniques used to simulate such systems may prove useful in further investigation of these processes (Shoda, Lee Tiernan \& Mischel, 2002; Smith \& Conrey, 2007; Van Rooy, 2009).

\section{Recognition of contemporary group life in shaping individual functioning}

In personality theorising there has been growing recognition that people's understanding of themselves, including their identity or self-view, may assist them in selecting situations and social roles that 'fit' these understandings. Often, though, in social psychology the emergence of identity is not necessarily considered to be a matter of choice to join this 
group or to take on a particular social role (e.g. Endler \& Magnusson, 1976; Roberts \& Caspi, 2003). In social psychology there is an eye to broader social and political forces and events that shape the salience and meaning of group boundaries and processes of inclusion ('us') and exclusion ('them'). These dynamic features of group life, which have received less attention in personality psychology, we argue will affect individual group members in (potentially) significant ways.

Along these lines, there is evidence that authoritarianism increased amongst American university students following the events of 11 September 2001 (Nagoshi, Terrell \& Nagoshi, 2007) and that views related to dominance increased amongst members of a political group rising to power (Liu, Huang \& McFedries, 2008). Furthermore, there are active processes by which identities are constructed. National stereotypes that define a country's culture (e.g. what we believe and value) influence the psychology of members of the nation including their personalities (e.g. social maturity and embodying the characteristics valued in society; Roberts \& Mroczek, 2008; see also Markus \& Kitayama, 1994), and mind and brain (see Kitayama \& Uskul, in press for a review of cultural neuroscience). Political leadership and the way leaders seek to align and influence people's understandings and reactions is another domain that has received attention (Reicher, Drury, Hopkins \& Stott, 2001; Turner, Reynolds \& Subašić, 2008). These broader political and social forces can shape the meaning of people's group identities and thereby come to affect individuals' understandings of who they are (i.e. values, beliefs, goals, aspirations).

Through changes in one's group memberships, new social norms, values and beliefs emerge that can influence attitudes and behaviour. As different people come to be defined as similar to oneself, there are new opportunities for social influence, the emergence of different background knowledge, and the formation of different self-views. The real implications of this analysis for personality psychology are only starting to be investigated but there is much to offer in relation to fleshing out the way the social self and its (in)stability influences individual continuity and change (and vice versa).

An obstacle to real engagement with these ideas, though, is the view that there is a stable 'essence' or 'core' within the person that is biologically determined (e.g. genes, temperament) and therefore 'set' remaining relatively stable across time and situations. Although the 'situation' may moderate the expression of such underpinnings it rarely is viewed as affecting the person's 'true' character. The question of change itself and the role of social identity, social norms and social influence in such change, ultimately confronts such an 'essence' argument.

As with 'boxology' in social cognition, there are more dynamic models of biology and gene expression emerging that recognise the impact of the social environment more explicitly (Roberts \& Jackson, 2008). The sociogenomic model of personality psychology, for example, places 'states' defined as situation specific perceiver-environment responses, as the main mediator in a model that includes environment, biology and traits. The way a person thinks, feels and behaves in particular situations over time is argued to affect both biology and the emergence of traits. Through the incremental effects of states neuroanatomical structures or gene expression and traits also can be changed. States are the central mediator in the model because 'environments cause changes in states that then affect changes in traits in a bottom-up fashion' (p. 1535). Roberts and Jackson (2008) offer a model of the person that is more consistent with emerging evidence from animal biology, medicine and behavioural genetics where gene expression is affected by personenvironmental interactions (see also Magnusson, 1999). 
These ideas are supported by recent work in neuroscience. As a function of 'states' such as working as a taxi driver or being a student, one's brain structures can vary in predictable ways. There is evidence that taxi drivers in London have a different brain structure (larger hippocampus in the posterior region) than bus drivers in the same city. The explanation offered is that while taxi-drivers have high demands for spatial processing, bus drivers do not because in their work they follow set routes (Maguire, Woollett \& Spiers, 2006). Furthermore, there is evidence that one's role as a student can impact on brain function with evidence that sitting a medical exam can produce learning-induced changes in the region of the brain involved in memory retrieval and learning (Draganski et al., 2006).

Obviously there are complex issues that emerge from this work, and there is no suggestion that change is simple. There is, however, an acceptance that systems that were for a long time considered stable and fixed are now being shown to be open to the interdependences between the person and the situation. There is emerging evidence that 'states' can play a fundamental role in shaping the person. Social psychology emphasises the role that the group and social processes play in shaping the mind and focuses more on the impact of 'group-states' on the person.

What is being proposed is a non-reductionist model of mind and behaviour where the causes of behaviour are not necessarily only located within an inner essence of the person (temperament, biology, limitations of the cognitive system; Turner \& Oakes, 1997). Many theories and models equate core aspects of one's psychology with constructs that are biologically based rooted in physiology and associated stable genetic causes. Most importantly, discussion of the significant role of 'states' opens up debate about the genuine impact of the environment and its interpretation, on the 'real' person. This shift is radical in its implications for personality psychology and psychology more generally.

\section{SUMMARY AND CONCLUSIONS}

Personality psychology and social psychology offer comprehensive theories and research methods to understand and explain human behaviour. This paper has explored themes central to both fields through the concept of interactionism and, in particular, dynamic interactionism. In personality psychology a distinction is made between mechanical interactionism and dynamic interactionism (e.g. Endler \& Magnusson, 1976). In explaining behaviour, mechanical interactionism examines the characteristics of the person and the characteristics of the situation and considers their independent and interactive effects. Dynamic interaction, in contrast, following its Gestalt roots, considers persons and situations as irreducible 'wholes' that need to be considered as one interdependent unit. Traditional and recent research on dynamic interactionism was reviewed in the first section of the paper.

In the second section of the paper the focus was on social psychology. There is a significant body of work in this field that also draws on Gestalt psychology. Currently these ideas are most comprehensively developed in social identity theory (Tajfel \& Turner, 1979) and self-categorization theory (Turner et al., 1987, 1994). In this work there is a focus on the individual ('I') and the group ('we') and the psychological processes that explain the shift from one level of self-definition or self-categorisation to the other (and vice versa). Through explaining these processes it is necessary to explain the way a perceiver gives the environment or stimuli (including the self) context-dependent meaning. 
In the third and final section, common themes in the two fields were identified and discussed. Importantly, both argue that it is the psychological meaning a person gives a situation or the social context that is an essential determinant of behaviour. There is also recognition of the possibility for change as well as continuity in the person across contexts. For social psychology, in particular, there has been a focus on the role of the group not only as a normal level of self-experience but also as a source of continuity and change. Links between these themes and other developments in psychology were explored (e.g. social cognition, neuroscience, and (epi-)genetics).

Although other papers have considered interactionism as an important point of connection between these two fields, this paper is novel in three main ways. First, because of its emphasis on dynamic interactionism and theories focused on these same issues in social psychology, in particular self-categorization theory (Turner et al., 1987, 1994). Second, because it offers an advance on the central question of dynamic interactionism how is the environment (that includes the perceiver) given meaning. Third, because it considers all aspects of the person (individual and group) and the way the group through social influence impacts on personhood (e.g. norms, values, feelings and actions). Overall, though we have outlined a more coherent interactionist framework that connects work in personality psychology and social psychology with other significant developments in understanding mind and behaviour. It is hoped that these connections will open up and stimulate new lines of theory and research on the non-reductionist, more situated or context-dependent view of the person.

\section{ACKNOWLEDGEMENTS}

This research was funded by an Australian Research Council Large Grant. We would like to thank Carolyn Newbigin, Luisa Batalha, Marco Perugini and two anonymous reviewers for their assistance with the manuscript and constructive and useful comments.

\section{REFERENCES}

Andersen, S. M., \& Chen, S. (2002). The relational self: An interpersonal social-cognitive theory. Psychological Review, 109, 619-645.

Angyal, A. (1951). A theoretical model for personality studies. Journal of Personality, 20, 131-142.

Asch, S. E. (1955). Opinions and social pressure. Scientific American, 193, 31-35.

Baumeister, R. F. (Ed.), (1999). The self in social psychology. Philadelphia, PA: Psychology Press.

Bizumic, B., Reynolds, K. J., Turner, J. C., Bromhead, D., \& Subašić, E. (2009). The role of the group in individual functioning: School identification and the psychological well-being of staff and students. Applied Psychology: An International Review, 58, 171-192.

Blass, T. (1984). Social psychology and personality: Toward a convergence. Journal of Personality and Social Psychology, 47, 1013-1027.

Branscombe, N. R., \& Doosje, B. (2004). Collective guilt: International perspectives. New York: Cambridge University Press.

Bruner, J. S. (1957). Going beyond the information given. In J. S. Bruner, E. Brunswik, L. Festinger, F. Heider, K. F. Muenzinger, C. E. Osgood, \& D. Rapaport (Eds.), Contemporary approaches to cognition (pp. 41-69). Cambridge, MA: Harvard University Press.

Burke, P. J. (1991). Identity processes and social stress. American Sociological Review, 56, 836-849.

Draganski, B., Gaser, C., Kempermann, G., Kuhn, H. G., Winkler, J., Buchel, C., et al. (2006). Temporal and spatial dynamics of brain structure changes during extensive learning. Journal of Neuroscience, 26, 6314-6317. 
Dweck, C. S. (1996). Capturing the dynamic nature of personality. Journal of Research in Personality, 30, 348-362.

Ekehammar, B. (1974). Interactionism in personality from a historical perspective. Psychological Bulletin, 81, 1026-1048.

Endler, N. S. (1982). Interaction comes of age. In M. F. Zanna, E. T. Higgins, \& E. P. Herman (Eds.), Consistency in social behaviour: The Ontario Symposium (Vol. 2, pp. 209-249). Hilsdale, NJ: Lawrence Erlbaum Associates.

Endler, N. S., \& Hunt, J. M. (1969). Generalizability of contributions from sources of variance in the S-R inventories of anxiousness. Journal of Personality, 37, 1-24.

Endler, N. S., \& Magnusson, D. (1976). Toward an interactional psychology of personality. Psychological Bulletin, 83, 956-974.

Endler, N. S., \& Parker, J. D. A. (1992). Interactionism revisited: The continuing crisis in the personality area. European Journal of Personality, 6, 177-198.

Goldberg, L. R. (1999). A broad-bandwidth, public-domain, personality inventory measuring the lower-level facets of several five-factor models. In I. Mervielde, I. Deary, F. De Fruyt, \& F. Ostendorf (Eds.), Personality psychology in Europe (Vol. 7, pp. 7-28). Tilburg, The Netherlands: Tilburg University Press.

Guimond, S., Branscombe, N. R., Brunot, S., Buunk, B. P., Chatard, A., Désert, M., et al. (2007). Culture, gender, and the self: Variations and impact of social comparison processes. Journal of Personality and Social Psychology, 92, 1118-1134.

Guimond, S., Chatard, A., Martinot, D., Crisp, R. J., \& Redersdorff, S. (2006). Social comparison, self-stereotyping, and gender differences in self-construals. Journal of Personality and Social Psychology, 90, 221-242.

Haslam, S. A., Ellemers, N., Reicher, S. D., Reynolds, K. J., \& Schmitt, M. T. (2010). Social identity perspective tomorrow: Opportunities and avenues for advance. In T. Postmes, \& N. R. Branscombe (Eds.), Rediscovering social identity: Core sources. New York: Psychology Press.

Haslam, S. A., Oakes, P. J., Turner, J. C., \& McGarty, C. (1995). Social categorization and group homogeneity: Changes in perceived applicability of stereotype content as a function of comparative context and trait favourableness. British Journal of Social Psychology, 34, 139-160.

Haslam, S. A., \& Turner, J. C. (1992). Context-dependent variation in social stereotyping 2: The relationship between frame of reference, self-categorization and accentuation. European Journal of Social Psychology, 22, 251-277.

Haslam, S. A., Turner, J. C., Oakes, P. J., McGarty, C., \& Hayes, B. K. (1992). Context-dependent variation in social stereotyping 1: The effects of intergroup relations as mediated by social change and frame of reference. European Journal of Social Psychology, 22, 3-20.

Higgins, E. T. (1989). Self-discrepancy theory: What patterns of self-beliefs cause people to suffer? In L. Berkowitz, (Ed.), Advances in experimental social psychology (Vol. 22, pp. 93-136). New York: Academic Press.

Hogan, R. (2009) Much ado about nothing: The person-situation debate. Journal of Research in Personality, 43, 249-249.

Kelman, H. C. (1958). Compliance, identification, and internalization: Three processes of attitude change. Journal of Conflict Resolution, 2, 51-56.

Kelman, H. C. (2006). Interests, relationships, identities. Annual Review of Psychology, 57, $27-$ 54.

Kitayama, S., \& Uskul, A.K. (in press) Culture, Mind, and the Brain: Current evidence and future directions. Annual Review of Psychology.

Kluckhohn, C., \& Murray, H. A. (1953). Personality formation: The determinants. In C. Kluckhohn, H. A. Murray, \& D. M. Schneider (Eds.), Personality in nature, society, and culture (pp. 53-67). New York: Knopf.

Koffka, K. (1935). Principles of Gestalt psychology. London: Routledge.

Lewin, K. (1935). A dynamic theory of personality. New York: McGraw-Hill.

Lewin, K. (1952). Field theory in social science: Selected theoretical papers. New York: Harper \& Row.

Liu, J. H., Huang, L., \& McFedries, C. (2008). Cross-sectional and longitudinal differences in social dominance orientation and right wing authoritarianism as a function of political power and societal change. Asian Journal of Social Psychology, 11, 116-126. 
Magnusson, D. (1999). Holistic interactionism: A perspective for research on personality development. In L. A. Pervin, \& O. P. John (Eds.), Handbook of personality: Theory and research (2nd ed., pp. 219-247). New York, NY: Guilford Press.

Magnusson, D., \& Törestad, B. (1993). A holistic view of personality: A model revisited. Annual Review of Psychology, 44, 427-452.

Maguire, E. A., Woollett, K., \& Spiers, H. J. (2006). London taxi drivers and bus drivers. A structural MRI and neuropsychological analysis. Hippocampus, 16, 1091-1101.

Marcia, J. E. (1980). Identity in adolescence. In J. Adelson (Ed.), Handbook of adolescent psychology (pp. 159-187). New York: Wiley \& Sons.

Mavor, K. I. (2004). Apples, oranges, and tomatoes? Comparing groups, persons, and other social entities and the identities that go with them. Paper presented at the 12th Annual Brisbane Symposium on Social Identity Brisbane, Australia.

Mavor, K. I., Reynolds, K. J., \& Skorich, D. P. (2010). Categorization, homogeneity, and attribution: Judgment context, out-person homogeneity and the actor-observer effect. (Unpublished manuscript), The Australian National University.

McAdams, D. P. (1996). Alternative futures for the study of human individuality. Journal of Research in Personality, 30, 374-388.

McGarty, C. (1999). Categorization in social psychology. London: Sage.

Markus, H. (1977). Self-schemata and processing information about the self. Journal of Personality and Social Psychology, 35, 63-78.

Markus, H. R., \& Kitayama, S. (1994). A collective fear of the collective: Implications for selves and theories of selves. Personality and Social Psychology Bulletin, 20, 568-579.

Markus, H., \& Wurf, E. (1987). The dynamic self-concept: A social psychological perspective. Annual Review of Psychology, 38, 299-337.

Mischel, W. (1973). Toward a cognitive social learning reconceptualization of personality. Psychological Review, 80, 252-283.

Mischel, W. (2004). Towards an integrative science of the person. Annual Review of Psychology, 55, $1-22$.

Mischel, W. (2009). From personality and assessment (1968) to personality science, 2009. Journal of Research in Personality, 43, 282-290.

Mischel, W., \& Shoda, Y. (1995). A cognitive-affective system theory of personality: Reconceptualizing situations, dispositions, dynamics, and invariance in personality structure. Psychological Review, 102, 246-268.

Murray, H. (1938). Explorations in personality. New York: Oxford University Press.

Nagoshi, J. L., Terrell, H. K., \& Nagoshi, C. T. (2007). Changes in authoritarianism and coping in college students immediately after the terrorist attacks of September 11, 2001. Personality and Individual Differences, 43, 1722-1732.

Oakes, P. J. (1987). The salience of social categories. In J. C. Turner, M. A. Hogg, P. J. Oakes, S. D. Reicher, \& M. S. Wetherell (Eds.), Rediscovering the social group: A self-categorization theory. Oxford/New York: Basil Blackwell.

Oakes, P. J., Haslam, S. A., \& Turner, J. C. (1994). Stereotyping and social reality. Oxford, UK \& Cambridge, MA: Blackwell.

Onorato, R. S., \& Turner, J. C. (2002). Challenging the primacy of the personal self: The case for depersonalized self-conception. In Y. Kashima, M. Foddy, \& M. J. Platow (Eds.), Self and identity: Personal, social, and symbolic (pp. 145-178). Mahwah, NJ, US: Lawrence Erlbaum Associates.

Onorato, R. S., \& Turner, J. C. (2004). Fluidity in the self-concept: The shift from personal to social identity. European Journal of Social Psychology, 34, 257-278.

Perugini, M., \& Prestwich, A. (2007). The gatekeeper: Individual differences are key to the chain from perception to behaviour. European Journal of Personality, 21, 303-317.

Plaks, J. E., Shafer, J. L., \& Shoda, Y. (2003). Perceiving individuals and groups as coherent: How do perceivers make sense of variable behaviour? Social Cognition, 21, 26-60.

Reicher, S. D., \& Haslam, S. A. (2006). Rethinking the psychology of tyranny: The BBC Prison Study. British Journal of Social Psychology, 45, 1-40.

Reicher, S. D., Drury, J., Hopkins, N., \& Stott, C. (2001). A model of crowd prototypes and crowd leadership. In C. Barker, A. Johnson, \& M. Lavalette (Eds.), Leadership and social movements (pp. 178-195). Manchester: Manchester University Press. 
Reynolds, K. J., \& Oakes, P. J. (2000). Variability in impression formation: Investigating the role of motivation, capacity and the categorization process. Personality and Social Psychology Bulletin, $26,355-373$.

Reynolds, K. J., Turner, J. C., Branscombe, N., \& Mavor, K. I. (2005). Self-categorization and personal identity: Integrating group and personality processes (Grant funded by the Australian Research Council). Canberra: The Australian National University.

Reynolds, K. J., Subašić, E., Bizumic, B., Turner, J. C., Branscombe, N., \& Mavor, K. I. (2009). Social identity and personality processes: Non-aboriginal Australian identity and neuroticism. Manuscript in preparation.

Reynolds, K. J., \& Turner, J. C. (2006). Individuality and the prejudiced personality. European Review of Social Psychology, 17, 233-270.

Roberts, B. W. (2009). Back to the future: Personality and assessment and personality development. Journal of Research in Personality, 43, 137-145.

Roberts, B. W., \& Caspi, A. (2003). The cumulative continuity model of personality development: Striking a balance between continuity and change in personality traits across the life course. In U. Staudinger, \& U. Lindenberger (Eds.), Understanding human development: Dialogues with lifespan psychology (pp. 183-214). Dodrecht: Kluwer.

Roberts, B. W., \& Jackson, J. J. (2008). Sociogenomic personality psychology. Journal of Personality, 76, 1523-1544.

Roberts, B. W., \& Mroczek, D. (2008). Personality trait change in adulthood. Current Directions in Psychological Science, 17, 31-35.

Shoda, Y., Lee Tiernan, S., \& Mischel, W. (2002). Personality as a dynamical system: Emergency of stability and distinctiveness from intra- and interpersonal interactions. Personality and Social Psychology Review, 6, 316-325.

Shoda, Y., Mischel, W., \& Wright, J. C. (1994). Intra-individual stability in the organization and patterning of behavior: Incorporating psychological situations into the idiographic analysis of personality. Journal of Personality and Social Psychology, 67, 674-687.

Smith, E. R., \& Conrey, F. R. (2009). The social context of cognition. In P. Robbins, \& M. Aydede (Eds.), Cambridge handbook of situated cognition (pp. 454-466). Cambridge University Press.

Smith, E. R., \& Conrey, F. R. (2007). Agent-based modeling: A new approach for theory building in social psychology. Personality and Social Psychology Review, 11, 87-104.

Smith, E. R., \& Semin, G. R. (2004). Socially situated cognition: Cognition in its social context. Advances in Experimental Social Psychology, 36, 53-117.

Smith, E. R., \& Semin, G. R. (2007). Situated social cognition. Current Directions in Psychological Science, 16, 132-135.

Spears, R., Jetten, J., \& Doosje, B. (2001). The (il)legitimacy of ingroup bias: From social reality to social resistance. In J. Jost, \& B. Major (Eds.), The psychology of legitimacy: Emerging perspectives on ideology, justice, and intergroup relations (pp. 332-362). New York: Cambridge University Press.

Stapel, D. A., \& Koomen, W. (2001). I, we, and the effects of others on me: How self-construal level moderates social comparison effects. Journal of Personality and Social Psychology, 80, 766-781.

Stapel, D. A., \& Van der Zee, K. I. (2006). The self salience model of other-to-self effects: Integrating principles of self-enhancement, complementarity, and imitation. Journal of Personality and Social Psychology, 90, 258-271.

Steele, C. M., \& Aronson, J. (1995). Stereotype threat and the intellectual test performance of African-Americans. Journal of Personality and Social Psychology, 69, 797-811.

Steele, C. M., Spencer, S., \& Aronson, J. (2002). Contending with group image: The psychology of stereotype and social identity threat. In M. Zanna (Ed.), Advances in experimental social psychology (Vol. 34, pp. 379-440). San Diego, CA: Academic Press.

Swann, W. B. Jr., \& Seyle, C. (2005). Personality psychology's comeback and its emerging symbiosis with social psychology. Personality and Social Psychology Bulletin, 31, 155-165.

Tajfel, H. (1972) Experiments in a vacuum. In J. Israel, \& H. Tajfel (Eds.), The context of social psychology (pp. 69-119). London: Academic Press.

Tajfel H. (Ed.). (1978). Differentiation between social groups: Studies in the social psychology of intergroup relations. London: Academic Press. 
Tajfel, H., \& Turner, J. C. (1979). An integrative theory of intergroup conflict. In W. G. Austin, \& S. Worchel (Eds.), The social psychology of intergroup relations. Monterey, CA: Brooks-Cole.

Turner, J. C. (1982). Towards a cognitive redefinition of the social group. In H. Tajfel (Ed.), Social identity and intergroup relations (pp. 15-40) Cambridge: Cambridge University Press.

Turner, J. C. (1985). Social categorization and the self-concept: A social cognitive theory of group behaviour. In E. J. Lawler (Ed.), Advances in group processes (Vol. 2, pp. 77-121). Greenwich, CT: JAI Press.

Turner, J. C. (1991). Social influence. Buckingham, UK: Open University Press.

Turner, J. C. (2006). What does social psychology say about changing people's behaviour? Paper presented at the ACT DET/ANU Workshop, Canberra, November.

Turner, J. C. (1987). Rediscovering the social group. In J. C. Turner, M. A. Hogg, P. J. Oakes, S. D. Reicher, \& M. S. Wetherell, Rediscovering the social group: A self-categorization theory (pp. 1941). Oxford: Blackwell.

Turner, J. C., Hogg, M. A., Oakes, P. J., Reicher, S. D., \& Wetherell, M. A. (1987). Rediscovering the social group: A self-categorization theory. Blackwell. Oxford and New York.

Turner, J. C., \& Oakes, P. J. (1997). The socially structured mind. In C. McGarty, \& S. A. Haslam (Eds.), The message of social psychology: Perspectives on mind in society (pp. 355-373). Blackwell Publishing. Malden, US.

Turner, J. C., Oakes, P. J., Haslam, S. A., \& McGarty, C. (1994). Self and collective: Cognition and social context. Personality and Social Psychology Bulletin, 20, 454-463.

Turner, J. C., \& Onorato, R. S. (1999). Social identity, personality, and the self-concept: A selfcategorizing perspective. In T. R. Tyler, \& R. M. Kramer (Eds.), The psychology of the social self. Applied social research (pp. 11-46). Mahwah, NJ, US: Lawrence Erlbaum Associates.

Turner, J. C., Reynolds, K. J., Haslam, S. A., \& Veenstra, K. J. (2006). Reconceptualising personality: Producing individuality through defining the personal self. In T. Postmes, \& J. Jetten (Eds.), Individuality and the group: Advances in social identity (pp. 1-36). Sage Publishers. London.

Turner, J. C., Reynolds, K. J., \& Subašić, E. (2008). Identity confers power: The new view of leadership in social psychology. P. 't Hart, \& J. Uhr (Eds.), Public leadership: Perspectives and practices (pp. 57-72). Canberra: ANU E-press.

Van Rooy, D. (2009). Modelling dynamic, multi-directional influences in social networks. In R. S. Anderssen, R. D. Braddock, \& L. T. H. Newham (Eds.), 18th World IMACS Congress and MODSIM09 International Congress on Modelling and Simulation Modelling and Simulation Society of Australia and New Zealand and International Association for Mathematics and Computers in Simulation, July (2009). (pp. 74-80). Cairns. Australia.

Wertheimer, M. (1938). Gestalt theory. In W. D. Ellis (Ed.), A source book of Gestalt psychology (pp. 1-11). New York: Harcourt (Original Work Published in 1924).

Williams, M. T., Turkheimer, E., Magee, E., \& Guterbock, T. (2008). The effects of race and racial priming on self-report of contamination anxiety. Personality and Individual Differences, 44, $746-757$. 